Original Research Paper

\title{
Gamification in E-Learning: Introducing Gamified Design Elements into E-Learning Systems
}

\author{
Daniel Strmečki, Andrija Bernik and Danijel Radošević \\ Faculty of Organization and Informatics, Pavlinska 2, 42000 Varaždin, Croatia
}

\author{
Article history \\ Received: 14-12-2015 \\ Revised: 09-02-2016 \\ Accepted: 10-02-2016 \\ Corresponding Author: \\ Daniel Strmečki \\ Faculty of Organization and \\ Informatics, Pavlinska 2, 42000 \\ Varaždin, Croatia \\ Email: danstrmecki@gmail.com
}

\begin{abstract}
Gamification is the usage of game mechanics, dynamics, aesthetics and game thinking in non-game systems. Its main objective is to increase user's motivation, experience and engagement. For the same reason, it has started to penetrate in e-learning systems. However, when using gamified design elements in e-learning, we must consider various types of learners. In the phases of analysis and design of such elements, the cooperation of education, technology, pedagogy, design and finance experts is required. This paper discusses the development phases of introducing gamification into e-learning systems, various gamification design elements and their suitability for usage in e-learning systems. Several gamified design elements are found suited for e-learning (including points, badges, trophies, customization, leader boards, levels, progress tracking, challenges, feedback, social engagement loops and the freedom to fail). Advices for the usage of each of those elements in e-learning systems are also provided in this study. Based on those advises and the identified phases of introducing gamification info e-learning systems, we conducted an experimental study to investigate the effectiveness of gamification of an informatics online course. Results showed that students enrolled in the gamified version of the online module achieved greater learning success. Positive results encourage us to investigate the gamification of online learning content for other topics and courses. We also encourage more research on the influence of specific gamified design elements on learner's motivation and engagement.
\end{abstract}

Keywords: E-Learning, Design, Gamification

\section{Introduction}

Gamification is a buzzword that has appeared in a few different fields in the last couple of years, including learning. The term does not imply the design of games, but the usage of game elements, game mechanics and game thinking in non-game contexts. Kapp defined gamification for learning as usage of game-based mechanics, aesthetics and game thinking to engage people, motivate action, promote learning and solve problems (Enders, 2013; Kapp, 2012). Mechanics are the functioning components of the game, a set of rules and feedback loops that make the game fun (Enders, 2013; Zichermann and Cunningham, 2011). Dynamics are the player's interactions with mechanics while aesthetics are how the game makes the player feel during those interactions (Zichermann and Cunningham, 2011). Some authors have also identified other game components like narration, storytelling, technology and interactivity.
Commonly used game elements in non-game systems include points, achievements, badges, leaderboards, levels, challenges, time-based activities, etc (Enders, 2013; Glover, 2013). The most common objective for using gamification is to increase user's motivation, experience and engagement (Domínguez et al., 2013). In psychology, we distinguish between two types of motivation. Intrinsic motivations are those that derive from our core self while extrinsic motivations are driven mostly by the world around us (Zichermann and Cunningham, 2011). As learning is an active process, it requires motivation to both begin and continue. Thus, gamification is being used in e-learning systems to motivate and engage learners. It makes use of competition instinct possessed by most people to encourage productive behavior. It has actually been used in teaching for many years, as some teachers used gold stars on posters next to student names. Besides competing, gamification can encourage a sense of pride 
and achievement in learners (Glover, 2013). Gamification can indeed provide several positive steps in modern e-learning systems, but we must also consider its application from the psychological point of view. There are individuals among us who do not like to play games, do not need additional motivation, consider it a waste of time or simply do not like to compete with others. All types of people and their learning habits must be considered when designing a modern e-learning system with gamified elements.

The rest of the article is structured as follows. We start with the presentation of related work in section 2 . Then we present five phases of introducing gamification into e-learning in section 3. Section 4 describes and analyses appropriate gamification design elements for elearning systems. Section 5 describes the conducted experimental research on the online module while section 6 displays the research data collection and results analysis. Finally, section 7 outlines the conclusions and gives recommendations for future work.

\section{Related Work}

In their book (Zichermann and Cunningham, 2011), identify four reasons why people play games: To master, to distress, to have fun and to socialize. On that basis, they have also identified four kinds of fun. Hard fun is when a player is trying to beat the competition. Easy fun is when a player is focused on exploring. Altered state fun changes the way the player feels and social fun engages him with other players. Authors have also made a contribution by identifying four player types. For explorers, an experience is the main objective. They like to go out into the world in order to bring things back to their community and then proclaim it. Achievers like to achieve things in a competitive environment. However, it is difficult to develop a system where everyone wins. Socializers play games for the benefit of a social interaction. Killers are similar to achievers, but for them winning isn't enough. They must win and someone else must lose. Authors assume that $75 \%$ of the population are socializers, $10 \%$ are achievers, $10 \%$ are explorers and $5 \%$ are killers. When designing a gamified system, it is important to understand why people play games and the differences between player types.

Self-Determination Theory (SDT) was first introduced by (Deci and Ryan, 1985) when they were describing the gap between intrinsic motivation and extrinsic motivation. Deci identified three primary elements in SDT: Need for competence, need for relatedness and need for autonomy. If those three were presented in the same time, the user might experience strong intrinsic motivation which is also a good indicator of a self-motivation (Hakulinen, 2015). SDT was taken into consideration for this research because it has the same psychological approach as gamification does. Its main idea relies on intrinsic motivation of the users, which is obtained through more enjoyable and engaging environment.

Universal Design for Learning (UDL) theory has its roots in the fields of architecture and neuroscience. The theory recognizes the promise of technology and its principles guide educators in finding innovative ways to make curriculum accessible and appropriate for different individuals and learning situations (Eagleton, 2008). According to Gillis and Matlock (2012) there are three key principles of UDL: Multiple means of representation, multiple means of expression and multiple means of engagement. Gamification is in conformity with UDL as it makes use of state-of-art technology and follows the same principles, especially by enabling multiple means of user engagement.

Enders (2013) in her paper proposes the usage of several gaming elements in e-learning systems including points, achievements, badges, leaderboards, levels, challenge, etc. The author provides many useful tips for the design of gamified e-learning systems, but more research on gamification elements effectiveness in elearning systems is required.

Wongso et al. (2014) in their paper propose a conceptual framework design, based on a social engagement in Web 2.0 technology and gamification. Their framework serves as a guideline for people who want to implement gamification and Web 2.0 technology in e-learning systems. It includes five phases: Analysis, design, development, implementation and evaluation.

Urh et al. (2015) provide a more complete model for gamification of e-learning systems in their paper. They have connected all of the previously listed development phases with the management of e-learning, important factors for e-learning, game mechanics, game dynamics, gamification elements and their effects on students. As the important factors for e-learning, the authors have included: Pedagogy, technology, design, administration, people, learning materials and finance. They argue that e-learning should be developed according to the modern development of web applications and that an e-learning system should include gamification. Their model for gamified e-learning is designed to maximize student satisfaction, motivation, effectiveness and efficiency.

Glover (2013) presented some interesting criticism of gamification in his paper. First of all, the educational experience should be rewarding by itself, only then gamification can make it more rewarding. Learners with high intrinsic motivation can be demotivated by extrinsic recognition ("the over-justification effect"). Therefore, gamification elements in e-learning should be carefully designed and optional per user. Gamification can discourage the less competitive learners and be counterproductive for those who find it a waste of time. The author has also pointed out the necessary 
considerations before implementing gamification in elearning. Those include questions like: Is motivation really a problem, are there behaviors to encourage, can an activity be gamified, would it favor some learners, what rewards would provide the most motivation, are rewards too easy to obtain? The author concludes that gamification can do little with low-quality materials, activities and experiences, but it can provide additional motivation with careful consideration of its implementation.

Domínguez et al. (2013) in their experiment with a gamification plugin in e-learning system found that students who completed the gamified experience got a better score in practical assignments, but performed poorly on written assignments. However, their system's design was far from perfect as students had problems accessing the gamification plugin (it was not fully integrated with their e-learning platform) and they had to manually upload screenshots which were then evaluated afterwards.

Ibanez et al. (2014) in their study of gamified learning of $\mathrm{C}$ programming language show very positive effects of gamification on learning. Authors have collected and analyzed both qualitative and quantitative data including logs, questionnaires, pretests and post-tests. Their results show that students continued their study even after reaching the learning goal, so their participation was beyond requirements. Only 2 out of 22 students in the study stopped their work once they achieved the necessary points. The engagement in gamified activity encouraged students to master unexplored topics and thus potentially improve their knowledge.

Considering that we have noticed in the literature (Domínguez et al., 2013; Ibanez et al., 2014) that most of the previous course gamification attempts have developed and used their own custom learning gamified platforms, we have decided to use an existing, popular and open-source e-learning platform for our research presented in sections 5 and 6 . We have chosen Moodle as the standard e-learning platform on our faculty and the world's most popular open source e-learning platform according to many online sources.

\section{Introducing Gamification into E-Learning}

For the successful design of gamified e-learning system it is necessary to understand the core concept of games: Goal focused activities, reward mechanisms and progress tracking. In e-learning systems, learners are directed to undertake certain tasks in order to achieve the desired goal. Thus, progress tracking and reward mechanisms can be used in e-learning to increase user's motivation and engagement (Glover, 2013). Proposed models for introducing gamification in e-learning agree that it is a project that can be related to software design. Thus, it should follow all phases of e-learning system development: Analysis, design, development, implementation and evaluation as displayed in Fig. 1 (Urh et al., 2015; Wongso et al., 2014).

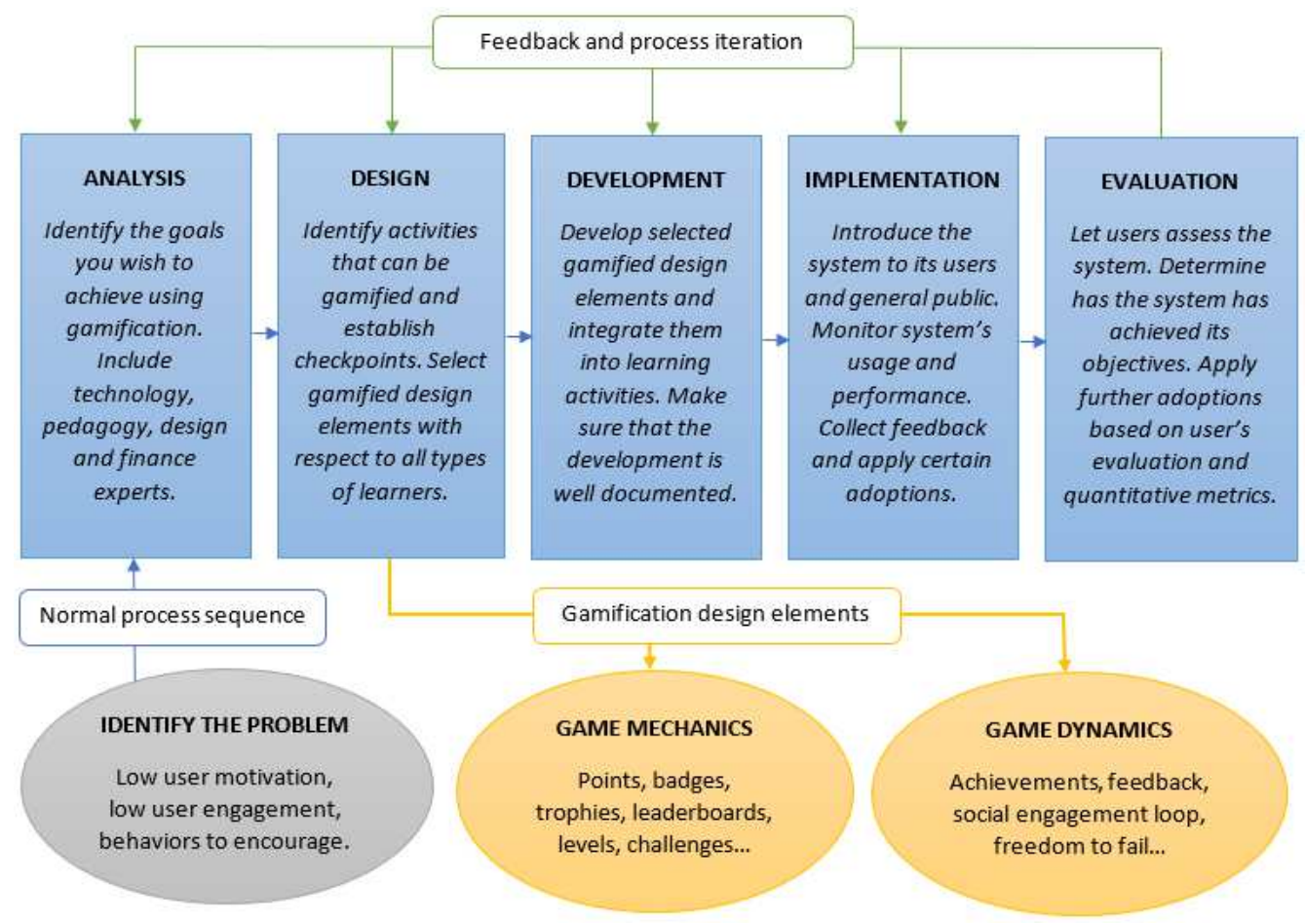

Fig. 1. Phases of introducing gamification into e-learning systems 
The analysis phase should include experts from various fields, including education, technology, pedagogy, design and finance. Facilitating learning and transferring knowledge and skills to students (educating) is the main objective of e-learning. Technology is the basic infrastructure that enables the implementation of elearning systems. Pedagogy, as a method and practice of teaching, takes care of educational quality, teaching values, learning and assessment activities supported by technology. Quality graphic design is a must have in systems that use gamified design elements. The lack of appropriate design can easily lead to unsuccessful implementation. Finance is an important part of every system's development, so the same applies for e-learning (Urh et al., 2015). In this phase, we should identify the goals that we wish to achieve using gamification.

If there is no need to increase user motivation, engagement or behaviors to encourage/discourage, then gamification probably isn't suited for our system (Glover, 2013). Some of the components that can be considered in this phase are: Player reengagement (periodical tasks), social calls, rewards, progress tracking, self-assessment, participation, communication and freedom to fail (Enders, 2013; Wongso et al., 2014).

Design is a crucial phase when introducing gamification into learning which this paper focuses on. It must be done on the basis of a good analysis (Urh et al., 2015). We need to identify activities that can be gamified and establish checkpoints in those activities that can identify learner's progress. When using gamified design elements, we need to make sure that we don't favor some learners over others. All gamified design elements in e-learning systems should be optional, in order to support learners with high intrinsic motivation. Reward mechanisms should be especially carefully designed to motivate everyone. Also, rewards should be achievable with a significant amount of effort, but not too easy (Glover, 2013). We need to make sure that our system in not too competitive, as most people are socializers, not achievers or killers. As instructors, we also need to help and lead our learners to their goals. This is especially important for beginners who are just getting to know the system. Even in an e-learning system, we can follow Zichermann and Cunningham (2011) advice: "Your player is on his own journey. You must make it your goal to help pave and structure that journey. To obtain long-term, enduring loyalty and connection from your players, you must guide them up the mountain. You don't need to be the mountain and you don't need to create it. You simply need to lead them up". In gamified systems design we influence student's cognitive, emotional and social areas. The design of the cognitive area of experience is a set of rules in which students must obtain certain skills. Virtual reward systems are used to impact student's emotional area: Score systems, experience points, items, resources, achievements, feedback, messages, animations and content. In order to impact student's social area, we can use cooperative, competitive and social interactions. Some of the most popular gamified elements that impact the social area are leaderboards and badges, because they can be displayed publicly (Domínguez et al., 2013). Gamified design elements that are suited for e-learning systems will be further analyzed in the next chapter.

The development phase comes after the system is successfully designed. This phase relies heavily on technology. E-learning systems are most commonly online web applications developed using technologies like: Ajax, ASP, Java, JavaScript, PHP, Ruby on Rails and others. Gamified elements are also developed using the same technology, often relying on Web 2.0 technology for better visual presentation (Urh et al., 2015; Zichermann and Cunningham, 2011). Besides development, two other crucial activities for this phase are documentation and testing. Urh et al. (2015) advise that: "A well-documented process of developing e-learning can assist us when dealing with repairing, adjusting and maintaining of e-learning and the overall project".

Implementation is a phase when the system is introduced to its users and the general public. This phase requires constant monitoring of system's usage as optimal system performance needs to be achieved. It is also very important to collect feedback from users and adopt certain features to their specific needs. Adoptions need to be quick with respect to all types of users (professors, tutors, administrative staff and learners). Implementation is one of the most difficult phases in e-learning and other web-based systems development (Urh et al., 2015).

In the evaluation phase, the users will assess the implemented system (Zichermann and Cunningham, 2011). Besides satisfaction surveys, there are several quantitative metrics that we can be used to analyze user's engagement: Page views per visitor, time spent on site, total time per user, frequency of visit, participation and conversations (Muntean, 2011). Based on the evaluation we can determine if the system has achieved its objectives. Usability of an e-learning system can be defined by five components: Learnability, efficiency, memorability, errors and satisfaction. Conclusions drawn from the evaluation phase can be used for further adoptions or even for decisions to make bigger changes to the system (Urh et al., 2015).

\section{Gamified Design Elements Suited for E- Learning}

Gamification had many successful applications in entertainment and business applications before its introduction to e-learning systems. One of the first 
successful gamification projects were airline loyalty programs, like American Airlines Frequent Flyer Program. These programs use game mechanics like points and miles which members earn for flying on the airline, as well as for using services from other partner companies (Enders, 2013). Foursquare had an incredibly successful implementation of the core game mechanics like points, levels, badges and leaderboards. This location-centric mobile application became famous for its badges. An interesting information is that $30 \%$ of all Foursquare badges are shared on Facebook (Zichermann and Cunningham, 2011). Adobe's Level Up is a free plugin for learning Photoshop that applies gamified elements. It enables users to work through a series of missions (for example: Reducing red-eye, whitening teeth, removing unwanted elements from a picture, etc.). For a successful completion of a mission, users are rewarded through game mechanics like points and badges (Enders, 2013). Nike Plus is a social running game for web and mobile platforms that employs sophisticated game mechanics to encourage runners. It uses a fun social loop over Facebook that reinforces the user's commitment to fitness. Application posts a Facebook feed on the start of the run and plays a burst of a roaring crowd over music once a friend likes that feed (Zichermann and Cunningham, 2011). Many other successful game mechanics implementations in entertainment and business can be found in the literature (Domínguez et al., 2013; Enders, 2013; Glover, 2013; Zichermann and Cunningham, 2011).

Most of the gamified design elements applied in the mentioned applications can also be applied in e-learning systems. But, when applying the same kind of game mechanics and dynamics in education, we need to be more careful and design them to fit various learning habits and types of personality. Some authors argue that gamification could even become a new learning theory by comparing it with the behaviorist, cognitivist, constructivist and connectivist approaches. According to Biro (2013): "As gamification addresses the contemporary pedagogical problems more effectively than the previous learning theories and has an extensive theoretical frame which covers the complete learning process with all relevant components, it must not be an exaggeration to define it as a new learning theory". Therefore, it is highly recommended consulting an expert in pedagogy or even psychology before implementing game mechanics and dynamics in an elearning systems. We will present common gamified design elements and discuss their suitability for usage in e-learning systems.

Points are used in education for centuries. Students receive points for their answers on the exam, which are then converted to grades from 1 to 5 (or A to F). Points in a gamified system are an absolute requirement. They can easily be converted to commitment/activity grades at the end of the academic/school year. Zichermann and Cunningham (2011) in their book distinguish five type of points: Experience points, redeemable points, skill points, karma points and reputation points. Experience points can be seen as overall progress points in elearning systems. Redeemable points are characteristic for social games and loyalty programs ("earn and burn" concept). They are unlikely to be used for learning purposes, except maybe for unlocking some additional content. Skill points can be seen as a set of bonus points that students can earn for additional activities. Karma points are points that do not affect the actual grade, but students can use them to gain status. For example, students can give karma points to other students for good answers on the forum, a good wiki page, etc. Gaining status in a virtual environment can be a powerful motivator for some people. Reputation points use a reputation system whose purpose is to act as a proxy for trust (Zichermann and Cunningham, 2011). Duo to their complexity and trust issues, reputation points are highly unlikely to be used in learning. Points are already commonly used in e-learning systems as indicators of progress on the course (experience points). However, they can additionally be used to unlock some content/awards (redeemable/bonus points), or for gaining status (karma points).

In most gamified systems, rewards are associated with badges or trophies (achievements). But earning a badge is not enough and we must ensure that our learners can show off their achievements. A profile page displaying earned and available badges or trophies is a must have for an e-learning system that uses achievements as rewards. A grayscale or blurred badge that indicates an achievement that a learner hasn't yet earned can be a powerful motivator. Besides, according to Enders (2013) "For this element to be effective, the reward or achievement must be meaningful to your learners and be somewhat difficult to obtain." People desire badges and trophies for all kinds of reasons. For some collecting is a powerful drive, others like surprises or pleasures when an unexpected reward shows up (Zichermann and Cunningham, 2011). When designing rewards like badges, make sure they are not ugly, boring or pointless. For a reward to fulfill its mission, it must be a designer's artwork, it should be fun and hard to get.

Customization may also be used in e-learning as a motivating feature or even as a reward. By allowing a learner to choose its own background, font-type or avatar, we can add value to their experience. According to many designers, customization is a powerful tool for increasing commitment and engagement. But, be careful because giving users too much choice is considered a bad design method. Learners should have some customization options, but they shouldn't become overwhelming (Zichermann and Cunningham, 2011). 
A leaderboard is usually a kind of scoreboard displaying players/learners results from top to bottom. Leaderboards are used in e-learning systems to motivate competitive learners. However, no one likes to be on the bottom of the scoreboard, so different approaches may be used. A leaderboard may display only a few of the best learners, but that approach may not motivate many others. One good approach is to provide multiple leaderboards for each activity and a cumulative leaderboard for all activities (Enders, 2013). Another good strategy for e-learning systems is to use a nodisincentive leaderboard. Such leaderboards are commonly used in social networks. It is a kind of leaderboard that always puts the player or learner in the middle. It doesn't matter how many points a learner has, there are usually a few learners with a better score and a few learners with a lower score, that can be displayed on top/bottom relative to his position to motivate him (Zichermann and Cunningham, 2011). According to Glover (2013) "Leaderboard is typically used in competitive activities, but it can also be used to encourage teamwork." As we have previously mentioned, most people are socializers, so straight leaderboards may only be effective in a truly competitive environment. Social types of leaderboards and leaderboards broken down by activities are better choices for the less competitive environments (Zichermann and Cunningham, 2011).

Levels indicate progress. They are characteristic to games, but in an e-learning system, we can think of topics and lessons as levels. Enders (2013) defined levels as "milestones that a player achieves by completing certain tasks". Levels need to be designed logically, meaning that learners can easily understand them. They should also be extensible, as we may want to expand our course in the future. Level balancing is a complex activity. Difficulty should be constantly tested and the learner's feedback is the key input for making decisions and changes. Progress bars are connected to levels and serve as a percentage based guide to learners (Zichermann and Cunningham, 2011). Glover (2013) pointed out that "Progress tracking is somewhat analogous to the provision of feedback within education. Good feedback should outline what the learner has done and give guidance on how to improve or advance in the future..." Progress tracking is a must have feature for gamified e-learning systems, as it provides instant feedback on learners progress and motivates most learners to continue, especially when approaching the end of the course. In an e-learning system, we should enable our learners to complete levels, not only to go through the content. However, access to content can be controlled using levels and of course, starting levels should be easier than others to engage the learner (Enders, 2013).

Challenges and quests give learners direction for what to do within the system and how to win rewards.
According to Zichermann and Cunningham (2011)

"Using challenges as an option somewhere in the body of the system can add depth and meaning for the player.". Challenges are not that commonly used in elearning systems, but they are an interesting design element and should be considered in a combination with rewards (badges or trophies). An interesting option for elearning systems may also be the design of cooperative challenges, as group reinforcement is a powerful motivation tool (Schonfeld, 2015). Learners must be rewarded for completing challenges and the rewards must be meaningful to them. Challenges should also vary in their length, difficulty and completion time (Enders, 2013).

Zichermann and Cunningham (2011) argue that feedback is one of the most straightforward and important game mechanics. They define it as "Returning information to players and informing them of where they are at the present time, ideally against a continuum of progress". Feedback is equally important for games as for e-learning systems. Our learners need to know if they are heading in the right direction. Feedback opportunities should be provided throughout the whole learning experience and not just on its end (Enders, 2013).

Social engagement loops may be used in e-learning systems to motivate learners to come back. This phenomenon cleverly implemented in previously mentioned Nike Plus application is defined by Zichermann and Cunningham (2011) as a loop in which "a motivating emotion leads to player re-engagement, which leads to a social call to action, which flows to visible progress and/or rewards, which loops back around to a motivating emotion".

Gamified e-learning systems should allow its learners freedom to fail. Learning from mistakes and previous experiences is a powerful learning tool. We should try to provide multiple attempts in our quizzes and tests whenever possible. After a failed attempt, our learners should receive positive instructional feedback and be encouraged to try again after some time (Enders, 2013).

Other gamified design elements that were not discussed in this study may also be found it the literature (Domínguez et al., 2013; Enders, 2013; Glover, 2013; Ibanez et al., 2014; Kapp, 2012; Nielson, 2013; Schonfeld, 2015; Urh et al., 2015; Zichermann and Cunningham, 2011). In this chapter, we have presented the gamified design elements that we consider most appropriate for usage in e-learning systems based on our experience and literature review. Some of those elements are already used in popular e-learning systems like Moodle (including progress bars, badges, scoreboards, levels and tasks), while others have just entered an experimentation phase. However, further research is advised in order to determine the influence of each gamified design element on learner's motivation and engagement. Various types of learners must be taken 
into account and gamification effectiveness on each of them should be investigated in greater details.

\section{Experimental Research Approach and Method}

All of the phases of introducing gamification into elearning systems, displayed in Fig. 1, were taken into consideration when e-learning system was tested for compatibility and necessary modifications. Through consulting with few of our University senior researchers, we have created, in the first phase, our target group and achievable goal with a foundation in reviewed literature. The second phase was aimed at the logical and visual designing of a gamified system as well as developing new learning materials that support this kind of activities. The third phase was planned and managed together with our students as they were introduced and got familiar with their role in the process. The system was adopted to give the students the freedom of choice. Also, their feedback was collected for us to track and evaluate. In addition to earlier statements, discussions for introducing gamification into e-learning and design advices, we have conducted experimental research on the Computer Graphics university course during the last academic year. We have created two pedagogically different versions of an e-learning course as is: Classical non-gamified and a gamified version of the course, with features like student's leaderboard, badges and certificates for accomplishment, among others. Learning topics for both versions of these e-learning courses were based on advanced Computer Graphics elements.

As we have already mentioned, we used Moodle as our e-learning platform for both the gamified and nongamified e-learning course. As with most of popular elearning platforms, there isn't many out-of-the-box support for gamification in Moodle, so we had to turn to official plugins. We have searched the moodle.org webpage for plugins from four categories: Achievement, Blocks, Reports and User interface. For each category, six or more plugins were taken into consideration for implementation in our gamified system. Our list has almost 30 plugins which are limited to the version of Moodle system 2.7., some of those plugins are: Engagement, quiz game, certificate, workflow, overview stats, etc. In the process of designing an e-learning course, we had to combine previously identified appropriate gamified elements for e-learning with elements available in Moodle that fit our research problem. In Table 1 we present gamified design elements corresponding to elements used in this research. It is necessary to state that both versions of the system, gamified and the non-gamified version, had access to learning materials in the form of text and illustrations, as well as access to forum discussions. Besides that, the nongamified version didn't have any elements that are mentioned bellow in Table 1 .

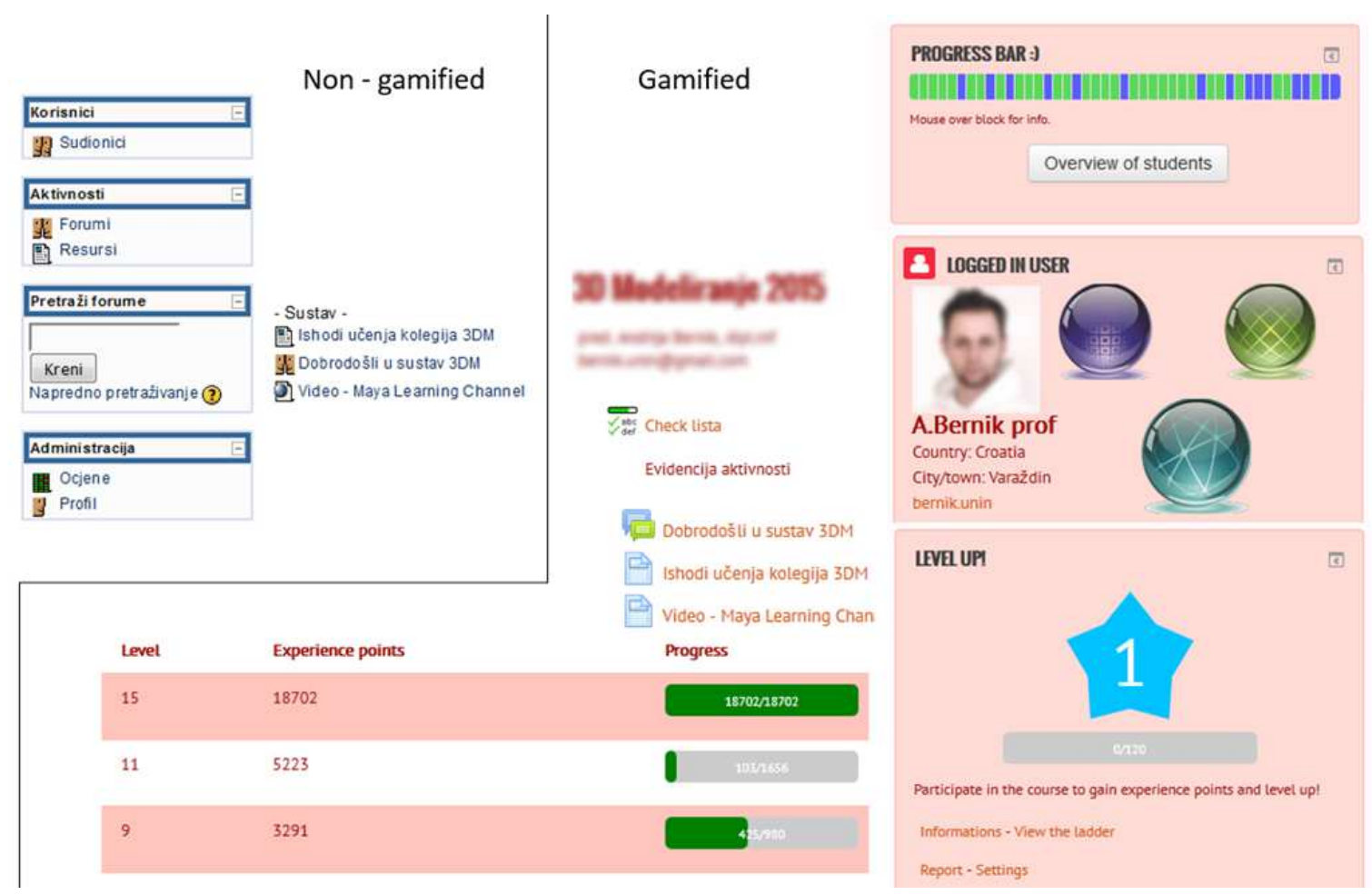

Fig. 2. Non-gamified (left) Vs. gamified system (right) 
Table 1. Gamified design elements used in e-learning course

Points

Points have a visual indicator of a granted level which is calculated on the base of time and student's activity in the e-course.

Badges

Badge in gamified e-course represents the achievements that relate to certain accomplishment. Each badge is rewarded when a certain set of activities is completed.

Customization Students have the ability to customize their avatar profile as well as their private information and position of system's elements. Some elements are possible to move around and make them visible on demand.

Leaderboards Leaderboard in the system shows all student names and every trackable activity. Students can see which activity is already passed by all other students, but they do not have the insight in each other's grades.

Levels Levels are attached to time management system and the base plan of the e-course. Levels are not created as a game looking change, but rather as chapters in a story.

Challenge Challenge is maintained as a checkpoint activity where students can test their knowledge and they can pass only if they have score above average.

Quest Quest inside the system is created as a one big problem. The problem is written down and shown to students and their mission is to get through the levels, challenges, earn points and badges and learn as much as they can in 2 weeks.

Feedback Feedback system is enabled in every activity that can be tracked. There is also a visual feedback for activities that need to be done, what is completed, what percentage of whole e-course is achieved, how many points and what level is student on, etc.

Freedom to fail Student is allowed to experiment on their own, there isn't any barrier on what is allowed to do, as well as when to do it. Inside any level, the student can access certain activities unlimited amount of time in the sake of learning. Challenge is open through the whole time that e-course is active, so students can go back and forward with testing their knowledge. If they fail to pass the test, they can go back and find needed answers, return to challenge activity and try it again. Questions are randomized every time and there are multiple answers as well as true or false statements.

For testing the gamification environment, we created two different systems which are shown on Fig. 2. The nongamified version had only basic design elements such as forum and lectures. Other gamified elements like progress bar, any kind of points or guidelines weren't available to users. On the other hand, the gamified version of the system was filled with visual trackers such as experience points, levels, leaderboards and guidelines for more efficient usage of the system. Users got the opportunity to receive badges for their achievements. Those achievements were described in detail along with the rules on how to get them.

\section{Research Data Collection and Analysis}

The main goal of our study was to investigate the effectiveness of gamification of an informatics online course in comparison with the conventional presentation of online learning content with only text and illustrations. We have formulated a hypothesis which states:

\section{H1: The use of the gamified online module by the experimental group will result in statistically significant greater average achievement measured by the post-test in comparison to the average achievement in the post-test of the control group that will use the parallel non- gamified version of this online module.}

We had a total of 55 students (31 male and 24 female) which were separated into four groups, two experimental study groups and two control study groups.
For gathering the needed information, we have created a questionnaire as well as pre- and post-tests. Pre-test was used for setting the groups to the same starting point considering their prior knowledge. After two weeks of using the systems students were presented with questionnaire aiming to give us the feedback about their experience and motivation. The questionnaire was held for $30 \mathrm{~min}$, followed by a post-test aiming to determine the significant difference between the groups. The research results are presented in the following section.

During the pre-test, the experimental group achieved the higher average score than the control group by 0.63 points (the difference in the average score on the pre-test between the two groups of subjects was not statistically significant). To analyze the difference between the experimental and control group regarding the average score on the post-test, the t-test for independent samples was used. The difference between those two groups for Mean was 5.59 and for Standard deviation was 1.28; both in favor of the experimental group.

The results of the t-test indicate that there is a statistically significant difference $(t=4.00, p<0.00)$ in favor of the experimental group regarding the average results of learning with the gamified version of the online course. This finding confirms the hypothesis (H1) of our study. The results of this study indicate that gamification of online courses related to Computer Graphics resulted in greater online course achievement. This finding encourages us to investigate the gamification of online learning content for other topics of the university course, as well as other ICT related courses of the authors of this paper. 


\section{Conclusion and Future Work}

The most common definition of gamification is that it is the usage of game mechanics in non-game systems. But besides mechanics, don't forget that it also includes dynamics, aesthetics and game thinking. Gamification's main objective is to increase user's motivation, experience and engagement. As learning requires high motivation, gamification design elements are interesting for implementation in e-learning systems. When using gamification in an e-learning system, it is important to consider various types of learners and their learning habits. Our focus cannot be turned only to socializers as the most common player type, instead, we must support all types of players/learners. Once we decide to introduce game mechanics and dynamics into an e-learning system we should follow all phases of e-learning system development: Analysis, design, development, implementation and evaluation. A key for successful gamification implementation is the correct selection of design elements and cooperation of experts in the fields of education, technology, pedagogy, design and finance. Various design elements were discussed in this article including points, badges, trophies, customization, leaderboards, levels, progress tracking, challenges, feedback, social engagement loops and the freedom to fail. Several design advices were provided for those elements, of which we would like to point out the following (Enders, 2013; Glover, 2013; Zichermann and Cunningham, 2011):

- Besides experience (progress) points, consider the usage of redeemable/bonus points for unlocking some additional content/awards or karma point for gaining status

- Rewards and achievements (badges or trophies) should be designer's artwork, fun and hard to get. Make sure that your learners can display and share their awards and achievements

- Give your learners some customization options, but remember that too much choice is bad

- Straight leaderboards may only be effective in a truly competitive environment. Instead, consider the usage of social types of leaderboards and leaderboards broken down by activities

- Make the starting levels easier than others. Enable progress tracking as it provides instant feedback on learner's progress and motivates them to continue

- Use challenges or even cooperative challenges and reward your learners for completing them

- Provide feedback throughout the whole learning experience. Your learners need to know if they are heading in the right direction

- Use social engagement loops to motivate your learners to come back soon

- Give your learners a freedom to fail and provide them with positive instructional feedback
Some of the mentioned design elements can already be found in popular open source e-learning platforms and thus we can use them free of charge. We used our findings and gamified design elements available in Moodle for our experimental study in order to investigate the effectiveness of gamification of an informatics online course. Results showed that students enrolled in the gamified version of the online module achieved greater learning success. Based on those results, in our future work, we will investigate the gamification of online learning content for other topics, as well as other ICT related courses. We will also try to identify the effectiveness of each gamified design element in elearning systems and strive to confirm the positive impact of gamification on learners in other courses, as we already observed in our experimental study and studies conducted by other authors (Domínguez et al., 2013; Ibanez et al., 2014).

\section{Acknowledgement}

The authors wish to thank Prof. D. Kermek, Ph.D. for motivating us for research in the field of gamification in e-learning and for the professor's helpful advices in early versions of the paper. Authors are also grateful to reviewers for their valuable comments and to $\mathrm{N}$. Tomašković for proofreading.

\section{Funding Information}

The research and publication were funded from the short-term research project support for 2015. of the University of Zagreb.

\section{Author's Contributions}

Daniel Strmečki: The main responsible author for literature review, identification of phases for introducing gamification into e-learning systems and advices on implementing gamification design elements in e-learning systems. Contributed in writing and research design.

Andrija Bernik: The main responsible author for design and implementation of experimental research. Contributed in writing, literature review, data collection and analysis of the results.

Danijel Radošević: The main responsible author for coordination, identifying contributions and publishing the paper. Contributed in writing, research design, organizing the structure and research supervision.

\section{Ethics}

This article is original and contains unpublished material. The corresponding author confirms that all of the other authors have read and approved the manuscript and no ethical issues involved. 


\section{References}

Biro, G.I., 2013. Didactics 2.0: A pedagogical analysis of gamification theory from a comparative perspective with a special view to the components of learning. Procedia-Social Behav. Sci., 141: 148-151. DOI: $10.1016 /$ j.sbspro.2014.05.027

Deci, E. and R.M. Ryan, 1985. Intrinsic Motivation and Self-Determination in Human Behavior. 1st Edn., Springer Science and Business Media, New York, ISBN-10: 0306420228, pp: 372.

Domínguez, A., J. Saenz-de-Navarrete, L. de-Marcos, L. Fernández-Sanz and C. Pagés et al., 2013. Gamifying learning experiences: Practical implications and outcomes. Comput. Educ., 63: 380-392. DOI: 10.1016/j.compedu.2012.12.020

Eagleton, M., 2008. Universal Design for Learning. EBSCO Publishing.

Enders, B., 2013. Gamification, games and learning: What managers and practitioners need to know. The e-learning Guild.

Gillis, A. and B. Matlock, 2012. Universal design for learning: Creating accessible learning environments. Grande Prairie Regional College.

Glover, I., 2013. Play as you learn: Gamification as a technique for motivating learners. Proceedings of the World Conference on Educational Multimedia, Hypermedia and Telecommunications, (MHT' 13), AACE, pp: 1999-2008.

Hakulinen, L., 2015. Gameful approaches for computer science education. Aalto University.

Ibanez, M.B., A. Di-Serio and C. Delgado-Kloos, 2014. Gamification for engaging computer science students in learning activities: A case study. IEEE Trans. Learn. Technol., 7: 291-301.

DOI: 10.1109/TLT.2014.2329293
Kapp, K.M., 2012. The Gamification of Learning and Instruction: Game-Based Methods and Strategies for Training and Education. 1st Edn., John Wiley and Sons, San Francisco, CA, ISBN-10: 1118096347 , pp: 302.

Muntean, C.I., 2011. Raising engagement in e-learning through gamification, Proceedings of the 6th International Conference on Virtual Learning, (CVL' 11).

Nielson, B., 2013. Gamification mechanics Vs. Gamification dynamics. Your Training Edge.

Schonfeld, E., 2015. SCVNGR's secret game mechanics playdeck. AOL Inc.

Urh, M., V. Goran, J. Eva and P. Rok, 2015. The model for introduction of gamification into elearning in higher Education. Procedia-Social Behav. Sci., 197: 388-397.

Wongso, O., Y. Rosmansyah and Y. Bandung, 2014. Gamification framework model, based on social engagement in e-learning 2.0. Proceedings of the 2nd International Conference on Technology, Informatics, Management, Engineering and Environment, Aug. 19-21, IEEE Xplore Press, Bandung, pp: 10-14. DOI: 10.1109/TIME-E.2014.7011583

Zichermann, G. and C. Cunningham, 2011. Gamification by Design: Implementing Game Mechanics in Web and Mobile Apps. 1st Edn., O'Reilly Media, Inc., Sebastopol, ISBN-10: 1449397670, pp: 182. 